\title{
In vivo three-dimensional kinematics of the normal knee during active extension under unloaded and loaded conditions using single-plane fluoroscopy
}

\author{
Tung-Wu Lu ${ }^{\text {a,*}}$, Tsung-Yuan Tsai ${ }^{\text {a }}$, Mei-Ying Kuo ${ }^{\text {a,b }}$, \\ Horng-Chaung $\mathrm{Hsu}^{\mathrm{c}}$, Hao-Ling Chen ${ }^{\mathrm{d}}$ \\ a Institute of Biomedical Engineering, National Taiwan University, No. 1, Section 1, Jen-Ai Road, Taipei 100, Taiwan, ROC \\ b Department of Physical Therapy, China Medical University, Taiwan, ROC \\ c Department of Orthopaedic Surgery, China Medical University Hospital, Taichung, Taiwan, ROC \\ d School of Occupational Therapy, National Taiwan University, Taiwan, ROC \\ Received 30 June 2007; received in revised form 27 January 2008; accepted 3 March 2008
}

\begin{abstract}
Measurement of the changes of the three-dimensional (3D) motion and surface kinematics of the knee under different external loading conditions is essential for the understanding and evaluation of the function of the joint, as well as for relevant clinical applications. Knee extension exercise (KEE) has been applied extensively in the rehabilitation programs of patients with various knee disorders. This study measured the 3D knee kinematics of eight normal subjects during active knee extension for unloaded and loaded conditions using a voxelbased method for the registration of fluoroscopic images with CT bone data. The knee kinematics during unloaded conditions were found to be similar to previous findings. A mass of $5 \mathrm{~kg}$ at the ankle did not affect the joint angles but significantly altered the lateral contact positions during knee extension, especially at knee flexion angles higher than $75^{\circ}$, and also reduced the asymmetry of the surface kinematics between the medial and lateral condyles. The results of the current study may be useful for knee replacement design and for developing guidelines for the use of KEEs for the rehabilitation of patients with knee disorders.
\end{abstract}

(C) 2008 IPEM. Published by Elsevier Ltd. All rights reserved.

Keywords: Knee; Kinematics; Fluoroscopy; Registration; Joint contact

\section{Introduction}

Measurement of the three-dimensional (3D) motion and surface kinematics of the knee during movement is essential for the understanding and evaluation of the function of the joint, as well as for relevant clinical purposes, such as the design and implantation of replacement joints [1-3], and the design of a suitable rehabilitation program for particular injuries [4,5]. Knee extension exercise (KEE), a non-weight-bearing, open kinetic chain exercise, has been applied extensively in the rehabilitation programs of patients with various knee disorders, such as knee OA [6] and patellofemoral pain syndrome [7], for patients following

\footnotetext{
* Corresponding author. Tel.: +886 2 33653335; fax: +886 233653335 .

E-mail address: twlu@ntu.edu.tw (T.-W. Lu).
}

anterior cruciate ligament (ACL) reconstruction [8], and for elderly people [9] to increase quadriceps muscle strength and improve physical function. However, some studies discouraged the use of KEE in certain conditions such as during the first year following ACL injury and reconstruction (e.g. [10]). It seems that the correct inclusion of KEE in rehabilitation programs requires a better understanding of the mechanics of the knee and effects of external loading during this exercise.

Providing a detailed description of the mechanics of the knee during KEE can be challenging because it is difficult to assess directly the forces transmitted in the force-bearing structures in vivo, including the articular surfaces, ligaments and muscles [11-15]. However, since the kinematics of the knee are a result of the complex interactions between the force-bearing structures, changes in the knee kinematics during KEE under different external loading conditions may be 
used to examine the overall response of these internal structures. An in vitro study has revealed the role of the ligaments and articular surfaces in determining the passive kinematics of the knee [16]. However, the effects of muscle activity in response to external loads on the knee kinematics during movement have not been studied extensively. This is because these conditions are difficult to simulate in vitro [17-19], and the accurate measurement of the in vivo 3D joint kinematics during dynamic movements is not straightforward [20-24]. To the best knowledge of the authors, no data have been reported on the effects of load on the in vivo 3D knee motion and surface kinematics during KEE.

Skin maker-based stereophotogrammetry has been widely used for the measurement of the in vivo 3D kinematics of human joints. However, errors due to undesired motion between markers and the underlying bones, called skin movement artifacts, are difficult to eliminate. The use of skin marker-based methods to describe joint surface kinematics during motion is also difficult because of the lack of joint surface information. Methods based on the registration of two-dimensional (2D) fluoroscopic images and computer models of the components of total knee replacements (TKRs) have recently been developed for accurate $3 \mathrm{D}$ kinematic analysis of replaced knee joints [25,26]. However, the application of this method to natural knee kinematics has been limited $[27,28]$ as human bones are of weaker contrast, and are thus more difficult to identify in fluoroscopic images, than metallic replacement components, leading to reduced accuracy. A voxel-based $2 \mathrm{D}$ to $3 \mathrm{D}$ registration method for more accurate measurement of the natural knee kinematics [29] can be a useful tool for the study of in vivo 3D knee motion and surface kinematics during KEE.

The purposes of the study were to measure the in vivo 3D motion and surface kinematics of the normal knee during KEE in unloaded and loaded conditions using single-plane fluoroscopy with a voxel-based 2D to 3D registration method. It was hypothesized that the knee kinematics in unloaded and loaded conditions during KEE would be different. It is hoped that these accurate and detailed descriptions of the knee kinematics during this exercise will be helpful for future clinical applications.

\section{Materials and methods}

\subsection{Subjects}

Eight normal subjects (age: $20.7 \pm 0.9$ years; mass: $64.8 \pm 5.5 \mathrm{~kg}$; height: $168.3 \pm 6.8 \mathrm{~cm}$ ), who were free from any disease of the neuromuskuloskeletal system, volunteered to participate in this study. Each subject gave his/her written informed consent before the experiment, clearance of which was carried out and approved by the Institutional Ethics Committee.

Each subject received a computed tomography (CT, PQ5000 , Picker International) scan over a range from $15 \mathrm{~cm}$ superior to the knee joint line to $15 \mathrm{~cm}$ inferior, with a slice thickness of $1 \mathrm{~mm}$ and a pixel size of $0.625 \mathrm{~mm} \times 0.625 \mathrm{~mm}$. The CT data were segmented by applying a threshold filter to the slices, and the external soft tissues were then digitally removed. The remaining CT data of the femur, tibia, fibula and patella were then used to obtain volumetric models of the individual bones. These subject-specific volumetric models preserved the scanned details of the bones, including their external surfaces and internal structures, and were necessary for subsequent registration with fluoroscopic images. With several million voxels, volumetric models are expected to describe the bones, and their positions and orientations at an accuracy higher than the voxel size that is the best point accuracy in CT [30].

\subsection{Experimental procedure}

Each subject sat on a chair and performed isolated active knee extension tests in unloaded and loaded conditions under dynamic fluoroscopic (Angiography, Advantx LCA, GE, France) surveillance, Fig. 1. Subjects were asked to extend their right knees from a fully flexed to a fully extended position at an average speed of about $70 \% \mathrm{~s}$ with the assistance of a metronome. In the loaded tests, a 5-kg mass was fixed to the ankle to impose a maximum moment of about $30 \mathrm{Nm}$ at the knee, which is a commonly prescribed rehabilitation activity aimed at training of the quadriceps [13]. The fluoroscopic video was converted to digital images at a sampling rate of $30 \mathrm{frame} / \mathrm{s}$ using an image grabber (PCI bus frame grabber, Foresight, USA).

\subsection{Fluoroscopy correction and calibration}

For the registration of the fluoroscopic images with the CT bone models, the fluoroscopy system was represented

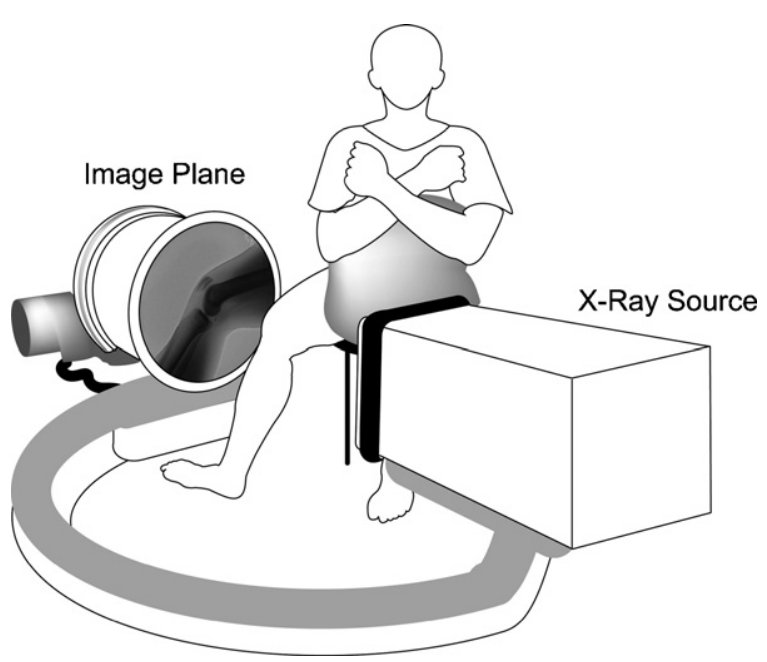

Fig. 1. Schematic diagram showing a subject performing active knee extension under dynamic fluoroscopic surveillance. An extra $5 \mathrm{~kg}$ mass would be fixed on the ankle for the loaded test conditions. 
by a perspective projection image formation model, with a point X-ray source and an image plane, i.e., the planar phosphor. All the fluoroscopic images were corrected for distortions through a calibration procedure based on a modified polynomial method [31] using images of a reseau plate $(21 \times 21$ lead markers at a grid interval of $25 \mathrm{~mm}$ ) placed on the intensifier tube. The mean (standard deviation) of the residual distortion errors after calibration was $0.07(0.03) \mathrm{mm}$. The position of the X-ray focus was determined by minimizing the sum of the projection errors of 160 lead markers distributed in a star shape on a calibration plate (marker-to-marker distance $=12.5 \mathrm{~mm}$ ) positioned $30 \mathrm{~cm}$ away from the reseau plate. The mean (standard deviation) of the projection errors was 0.13 (0.05) $\mathrm{mm}$.

\subsection{Registration procedure}

With the perspective projection model of the fluoroscopy system, the registration of the voxel-based CT-to-fluoroscopy images was performed by comparing systematically the fluoroscopic image with simulated 2D synthetic X-ray images of the bone model called a digitally reconstructed radiograph (DRR) [32], Fig. 2. A DRR was generated by casting Xrays through the volumetric $\mathrm{CT}$ data of a bone model and projecting onto the image plane to form an image resembling a radiograph with detailed internal information of the bony structures [33]. The 3D poses of the bones at each image frame were obtained by searching for the pose of the bone model using an optimization procedure to produce the DRR which best matched the fluoroscopic image. A computer

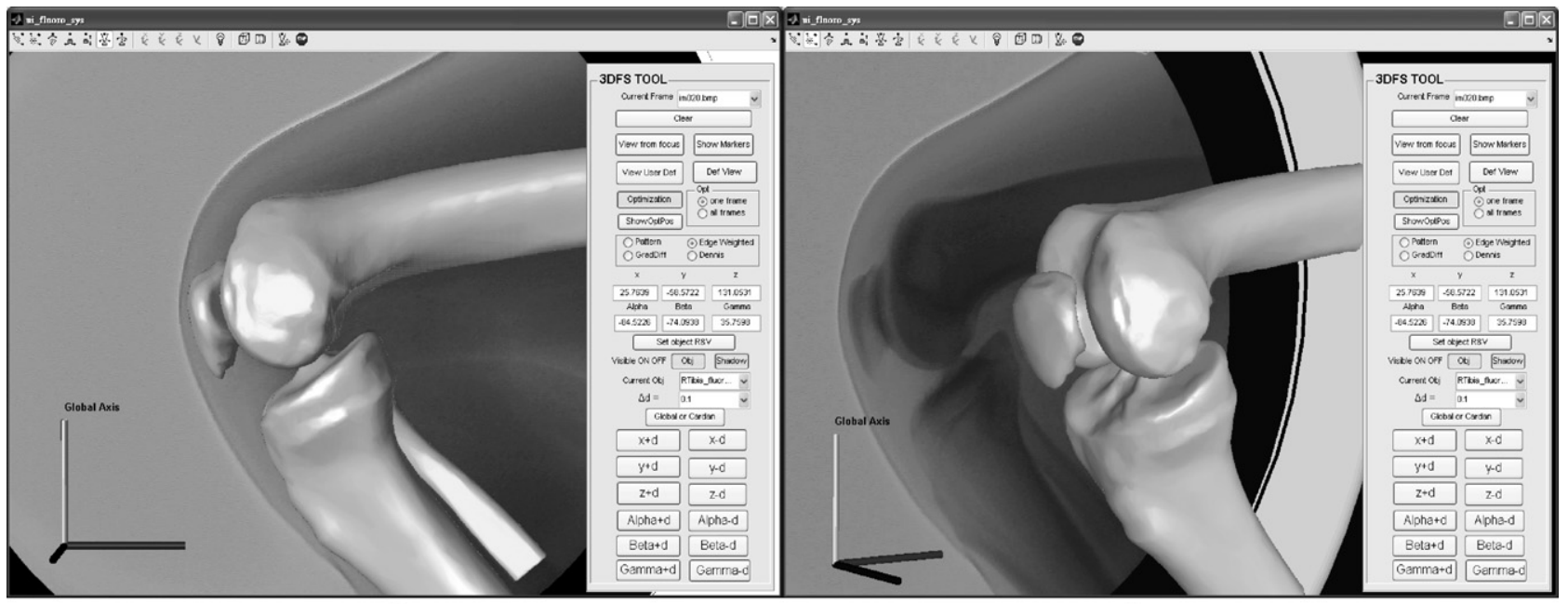

(a)

(b)



(c)

(d)

Fig. 2. The computer graphics user interface (GUI) program to assist the visualization of the registration and reconstruction of the 3D bone kinematics. The fluoroscopy image can be reconstructed and, with the imported CT data of the bone(s), digitally reconstructed radiographs (DRRs) are generated on the image plane for automatic registration through an optimization procedure. A surface rendered registered knee joint is shown from (a) the front and (b) the oblique view, and the corresponding DRRs are given in (c) and (d). 



Fig. 3. The mean internal/external rotation (I/E) and abduction/adduction (Abd/Add) angles, and posterior/anterior (P/A) and medial/lateral (M/L) translations with respect to the knee flexion angle during ( $a$ and $b$ ) unloaded and ( $c$ and d) loaded conditions. Shaded areas indicate one standard deviation.

graphics user interface (GUI) was developed to assist with the visualization of the registration and reconstruction of the 3D bone kinematics (Fig. 3). The registration method had previously been evaluated for its accuracy using a cadaveric knee, giving means and standard deviations of the knee kinematics errors of $0.24 \pm 0.77 \mathrm{~mm}, 0.41 \pm 3.06 \mathrm{~mm}$ and $0.59 \pm 1.13^{\circ}$ for in-plane translation, out-of-plane translation, and all rotations, respectively, over 11 flexion positions ranging from $0^{\circ}$ to $100^{\circ}$ [29].

\subsection{Data analysis}

The registered poses of the femur and tibia were used to calculate the 3D kinematics of the knee, including joint rotations and translations, as well as contact points and slip ratios of the articular surfaces, described as follows.

Joint angles were calculated as the relative rotations between the local coordinate systems of the femur and tibia. Since the CT scans of the bones were performed at full knee extension, the local coordinate systems of both bones were taken to be coincident with each other and originated at the most posterior point of the tibial attachment of the ACL. This definition indicated that the knee joint had zero rotational angles and translations at the fully extended position, which matched clinical definitions. The positive $Z$-axis was defined to be parallel to the inter-epicondylar axis and directed to the right. The positive $X$-axis was normal to the plane defined by the $Z$-axis and the longitudinal axis of the femur and directed anteriorly. The positive $Y$-axis was orthogonal to both the
$Z$ - and $X$-axes, following the right-hand rule, and directed superiorly. The rotational angles were then obtained using a cardanic sequence of $Z-Y-X$ [16]. The translations were defined as the displacements between the origins of the two local coordinate systems and were expressed relative to the tibial coordinate system.

Contact points of the medial and lateral femoral condyles on the corresponding compartments of the tibial plateau and the slip ratios between the articular surfaces were used to describe the surface kinematics of the tibiofemoral joint. For the description of the contact patterns, the origin of the tibial coordinate system was set at the center of an ellipse that best fitted the tibial plateau using points on the articulating surfaces. Contact points on one articular surface were estimated as the centroid of the contact area defined by the points that were within a distance of $2 \mathrm{~mm}$ from the corresponding points on the other articular surface. This may be considered as a first approximation of possible cartilage deformations, and the resulting contact point can be related to the center of the contact pressure. Previous studies have used the lowest point of the femur, assuming a flat tibial plateau, and the point with minimal distance between the articular surfaces to determine the contact points $[28,34,35]$. Both methods assume point contact between the articular surfaces, which may be sensitive to rough surfaces associated with the noise from the CT data.

The slip ratio was defined as the ratio of the length of the femoral articulation between two successive contact points and the length of the tibial articulation between the corre- 
Table 1

The means (standard deviations) of the total displacements of the medial and lateral contact points in the anterior-posterior and medial-lateral directions during unloaded and loaded conditions

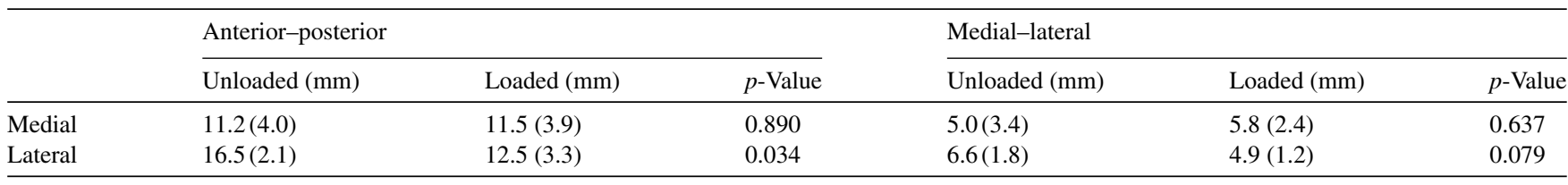

sponding contact points [36]. A slip ratio of 1 indicates pure rolling and 0 indicates pure sliding. The slip ratios were calculated at $15^{\circ}$ intervals, up to $120^{\circ}$ knee flexion. Interpolation of the contact points was used when the data points did not correspond to the intervals. To quantify the bilateral asymmetry of medial and lateral condylar slip ratios, a symmetry index (SI) was used and defined as follows [37]:

SI $(\%)=\frac{(\text { medial slip ratio }- \text { lateral slip ratio })}{(\text { medial slip ratio }+ \text { lateral slip ratio }) / 2} \times 100$

An SI value of 0 indicates perfect bilateral symmetry.

\subsection{Statistical analysis}

For all calculated variables, paired $t$-tests were performed to test for differences between conditions using SPSS Version 11.0 (SPSS Inc., Chicago, USA). The significance level was set at $\alpha=0.05$.

\section{Results}

No statistically significant differences in the average speeds were found between the two test conditions $(p=0.5367)$. During unloaded active knee extension, the tibia rotated externally by about $8.8^{\circ}$ from $114^{\circ}$ to $30^{\circ}$ knee flexion, and by about $10^{\circ}$ during the terminal $30^{\circ}$ of flexion (Fig. 3a). The knee remained at about $5^{\circ}$ adduction before returning to neutral during the terminal $30^{\circ}$ (Fig. 3a). The reference point on the femur translated relative to the tibia by a mean of $29.6 \mathrm{~mm}$ anteriorly, $19.9 \mathrm{~mm}$ distally, and $4.9 \mathrm{~mm}$ laterally as the knee extended (Fig. 3b). Under the loaded condition, the angular and translational motion curves were statistically the same as those during the unloaded condition, although the mean joint rotation curves appear to be different for flexion angles greater than $75^{\circ}$ (Fig. $3 \mathrm{c}$ and d).

Contact points on the medial and lateral tibial plateau moved anteriorly during knee extension during both loading conditions (Fig. 4a and b). The total anterior-posterior
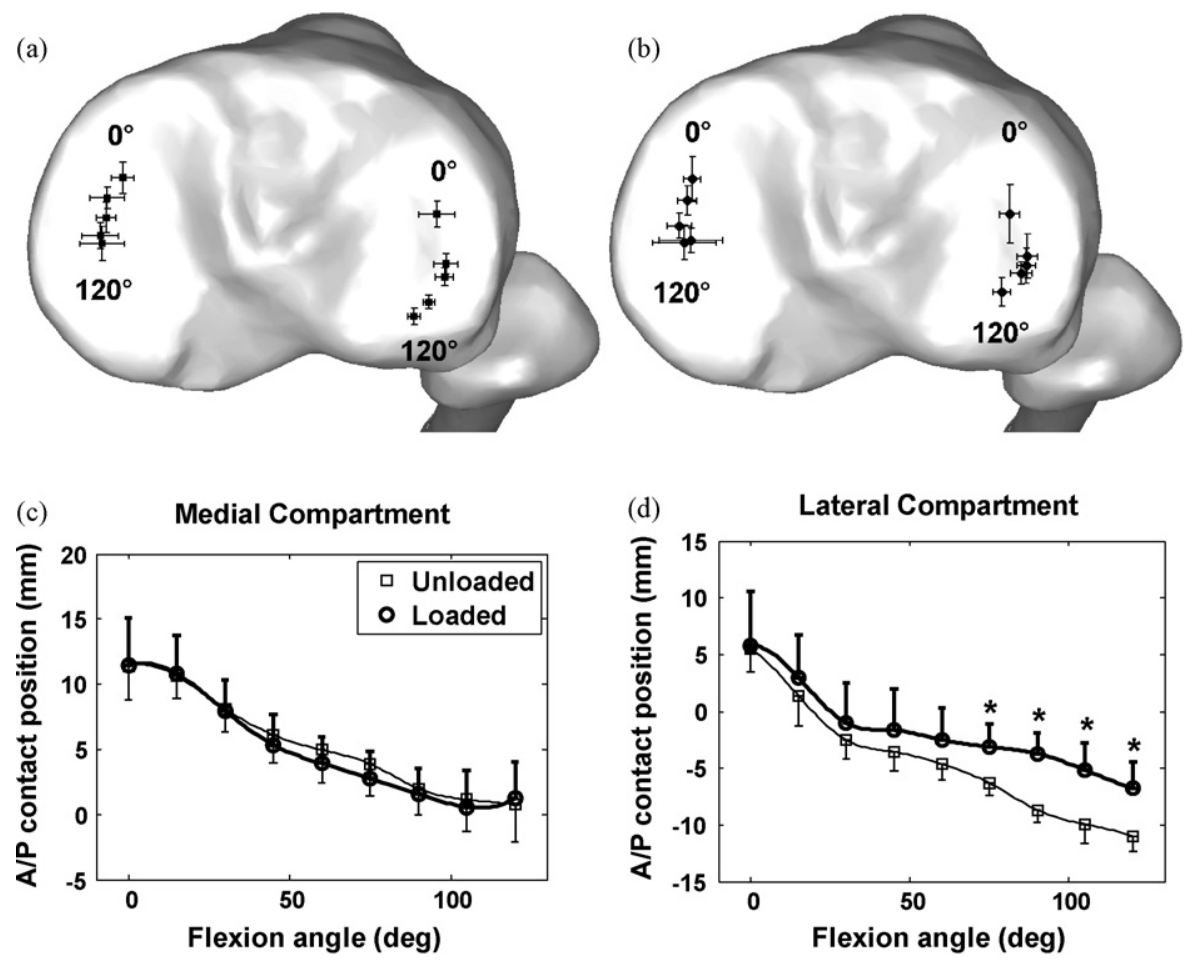

Fig. 4. The mean positions of the contact points on the tibial plateau under (a) unloaded and (b) loaded conditions at intervals of $30^{\circ}$, up to $120^{\circ}$ knee flexion. Comparisons of the contact positions between unloaded (thin, square markers) and loaded (thick, circular markers) conditions are shown in (c) for the medial and (d) for the lateral condyle. Error bars indicate one standard deviation $(* p$-value $<0.05)$. 

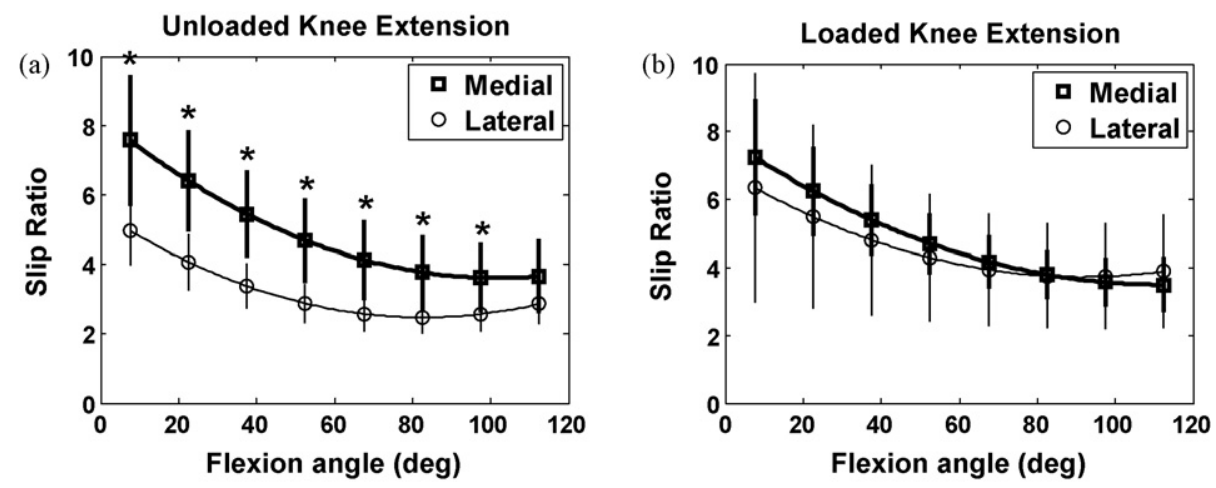

Fig. 5. Slip ratios of the medial (thick, square markers) and lateral (thin, circular markers) condyles during (a) unloaded and (b) loaded conditions. Error bars indicate one standard deviation (* $p$-value $<0.05$ ).

and medial-lateral displacements of the contacts in both tibial compartments were not significantly different between loading conditions, except for the total anterior-posterior displacements of the lateral contact during the loaded condition being significantly smaller (Table 1 , Fig. $4 \mathrm{a}$ and b). At $75^{\circ}$, $90^{\circ}, 105^{\circ}$ and $120^{\circ}$ of knee flexion, the lateral contact points under the loaded condition were more anterior than during the unloaded condition (Fig. 4d), while the medial contact points were not significantly different between loading conditions (Fig. 4c).

Slip ratios for both medial and lateral condyles at $15^{\circ}$ intervals are shown in Fig. 5. During unloaded extension, the slip ratios of the medial compartment were all significantly greater than those of the lateral, except for the $105^{\circ}-120^{\circ}$ interval (Fig. 5a). The slip ratios of the medial compartment were less than 4 for flexion angles greater than $60^{\circ}$ and increased to a maximum mean value of 7.6 for flexion angles less than $60^{\circ}$, while the corresponding slip ratios for the lateral compartment were 2.5 and 4.9, respectively (Fig. 5a). Under the loaded condition, the slip ratios of the medial compartment were not significantly changed, but those of the lateral side were increased throughout the whole range of extension and became statistically the same as those of the medial side. This change was also reflected in the SI values of the medial and lateral slip ratios. Under the loaded condition, the asymmetry of the slip ratios between the two compartments was largely reduced, with significance in the range between about $40^{\circ}$ and $80^{\circ}$ (Fig. 6).

\section{Discussion}

During unloaded knee extension, the tibia rotated externally with decreasing flexion angle, and about half of the total range of external rotation (about $10^{\circ}$ ) occurred during the terminal $30^{\circ}$ (Fig. 3a), corresponding to the so-called screwhome mechanism $[16,18,38,39]$. Patterns of the angular and translational displacements of the knee were also similar to those during passive motion reported in a cadaveric study [16]. A longer path for the lateral contact on the convex tibial plateau was found in the current study (Table 1), in agreement with previous reports $[28,34]$. The longer path contributed to the tibial external rotation during knee extension but, apart from articular surfaces, ligaments also play an essential role in guiding the motion of the femur relative to the tibia as shown by Wilson et al. [16]. Although contact movement paths provided some information about the surface kinematics of the joint, the slip ratio, proposed by O'Connor et al. [36], combined the information of the contacts on the tibial and femoral articular surfaces and provided more insight into the relative motion between these articular surfaces. During active knee extension, the slip ratios varied with flexion angle, and those of the medial condyles were generally greater than those of the lateral, but nowhere is the slip ratio equal to unity, corresponding to pure rolling. With a 4-bar linkage model of the knee, O'Connor et al. [36] reproduced the backward rolling and forward sliding motion of the femur on the tibia during passive knee flexion, and the slip ratio was used to quantify the relative motion of the femoral and tibial articulations. The

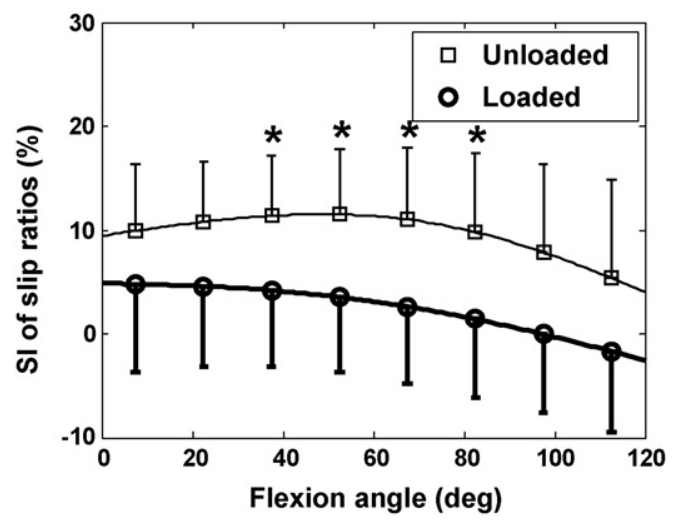

Fig. 6. SI of the medal and lateral slip ratios against knee flexion angles between unloaded (thin, square markers) and loaded (thick, circular markers) conditions ( ${ }^{*} p$-value $\left.<0.05\right)$. 
slip ratios obtained in the current study were in agreement with those reported by O'Connor et al., except that higher values were found for low flexion angles in the current study. This may have to do with the involvement of muscles in the current study.

During loaded knee extension, the patterns of the joint angles and translations were statistically similar to those during the unloaded condition, while the contact positions in the lateral compartment were significantly different for flexion angles higher than $75^{\circ}$ (Fig. 4d). These results appear to suggest different effects of load on the joint kinematics. However, since the bone-embedded coordinate systems were consistently attached to bones for all the subjects, the results may be due to the fact that the surface kinematics are determined by both the rigid-body kinematics and the articular surface geometry. Under the constraints of the articular surfaces, changes of contact positions under loading appeared to be more consistent between subjects than the rigid-body kinematics.

The change in the lateral contact reduced the total displacement of the contact path (Table 1) and led to the increase of the lateral slip ratios (Fig. 5b), which further decreased the asymmetry of the slip ratios between the two compartments (Fig. 6). Between $75^{\circ}$ and $90^{\circ}$ flexion, as the femur was horizontal and fixed relative to the chair, the lower leg and the weight were in front of the knee joint, generating an extensor moment at the knee. Since the patellar tendon is directed posteriorly at these angles [40], it pulled the tibia posteriorly while balancing the external moment. At flexion angles greater than $90^{\circ}$, the weight and the lower leg would cause a flexor moment at the knee, requiring the contractions of the hamstrings, which would also pull the tibia posteriorly. These posterior shear forces in response to the external weight would lead to the more anterior movement of the contact points on the tibial plateau during the loaded condition. The reason why the contact position changes occurred in the lateral compartment may be related to the net effects of the muscle and ligament forces on the external tibial rotation, including the patellar tendon and posterior cruciate ligament (PCL) forces. The shape differences of the two tibial plateaus also contributed to the observed phenomenon. While the anterior displacement of the contact in the anterior part of the concave medial plateau will increase the articular resistance to posterior shear forces and reduce the loads in the PCL, that in the posterior part of the convex lateral plateau will have the opposite effects [41].

The anterior shift of the contact points may lead to a greater load in the PCL or lateral collateral ligament because these two ligaments provide the posterior and lateral stability of the knee joint. These reasons suggest that KEEs at higher flexion angles may not help in protecting an injured PCL or a PCL graft, but they may be safe for training in ACL-deficient patients. External loads appeared to reduce the relative motions of the femoral and tibial articular surfaces between medial and lateral compartments, as revealed by the reduced SI of slip ratios. These changes in joint surface kinematics may be relevant to the rehabilitation of patients with knee OA. The 3D in vivo data on the knee motion and surface kinematics in the current study may also be helpful for theoretical estimation of the forces transmitted in the knee joint during active KEEs for the rehabilitation of patients with knee injuries [11]. These data may also provide a useful reference for future knee replacement design.

The voxel-based method used in the current study for the registration of the fluoroscopic images with the CT bone models was shown to be highly accurate, with sub-millimeter accuracy in in-plane (i.e., anterior-posterior) translations. Therefore, the changes on the surface kinematics could be obtained. Although not as accurate as "quasi-static" measurements using roentgen stereophotogrammetric analysis (RSA), CT or MRI, the method has the advantage of measuring more natural knee motions in 3D, dynamic, and weight-bearing conditions. Further study may include investigation of the effects of higher loads on the knee kinematics, and the estimation of the forces transmitted by the forcebearing structures by combining the accurate in vivo knee kinematic data with an appropriate knee model. A more advanced fluoroscopy system may be needed for the study of faster knee motions.

\section{Conclusions}

In vivo 3D knee motion and surface kinematics during active knee extension under unloaded and loaded conditions were measured using single-plane fluoroscopy with CT bone models. The knee kinematics during the unloaded condition were similar to previous findings. A weight at the ankle did not affect the joint angles but did significantly alter the lateral contact positions during knee extension, especially at knee flexion angles higher than $75^{\circ}$, and also reduced the asymmetry of the surface kinematics between the medial and lateral condyles. The results may be useful for knee replacement design and for developing guidelines for the use of KEEs for rehabilitation purposes.

\section{Acknowledgments}

The authors gratefully acknowledge the financial support from the National Science Council of Taiwan (NSC-94-2213E-002-112). We are also grateful for the staff of the Medical Imaging Department at China Medical University.

\section{Conflict of interest}

We, Tung-Wu Lu, Tsung-Yuan Tsai, Mei-Ying Kuo, Horng-Chaung Hsu and Hao-Ling Chen, declare that we have no proprietary, financial, professional or other personal interest of any nature or kind in any product, service and/or 
company that could be construed as influencing the position presented in, or the view of, the manuscript entitled, "In vivo three-dimensional kinematics of the normal knee during active extension under unloaded and loaded conditions using single-plane fluoroscopy."

\section{References}

[1] Coughlin KM, Incavo SJ, Doohen RR, Gamada K, Banks S, Beynnon BD. Kneeling kinematics after total knee arthroplasty: anterior-posterior contact position of a standard and a high-flex tibial insert design. J Arthroplasty 2007;22:160-5.

[2] Muratoglu OK, Rubash HE, Bragdon CR, Burroughs BR, Huang A, Harris WH. Simulated normal gait wear testing of a highly cross-linked polyethylene tibial insert. J Arthroplasty 2007;22:435-44.

[3] Kessler O, Durselen L, Banks S, Mannel H, Marin F. Sagittal curvature of total knee replacements predicts in vivo kinematics. Clin Biomech 2007;22:52-8.

[4] Schmalz T, Blumentritt S, Wagner R, Junge R. Evaluation with biomechanical gait analysis of various treatment methods after rupture of the anterior cruciate ligament. Sportverletz Sportschaden 1998;12: $131-7$.

[5] DeVita P, Hortobagyi T, Barrier J. Gait biomechanics are not normal after anterior cruciate ligament reconstruction and accelerated rehabilitation. Med Sci Sports Exerc 1998;30:1481-8.

[6] Huang M-H, Lin Y-S, Yang R-C, Lee C-L. A comparison of various therapeutic exercises on the functional status of patients with knee osteoarthritis. Semin Arthritis Rheum 2003;32:398-406.

[7] Witvrouw E, Danneels L, Van Tiggelen D, Willems TM, Cambier D. Open versus closed kinetic chain exercises in patellofemoral pain: a 5-year prospective randomized study. Am J Sports Med 2004;32:1122-30

[8] Snyder-Mackler L, Delitto A, Bailey SL, Stralka SW. Strength of the quadriceps femoris muscle and functional recovery after reconstruction of the anterior cruciate ligament. A prospective, randomized clinical trial of electrical stimulation. J Bone Joint Surg Am 1995;77:116673.

[9] Ferri A, Scaglioni G, Pousson M, Capodaglio P, Van Hoecke J, Narici MV. Strength and power changes of the human plantar flexors and knee extensors in response to resistance training in old age. Acta Physiol Scand 2003;177:69-78.

[10] Bynum EB, Barrack RL, Alexander AH. Open versus closed chain kinetic exercises after anterior cruciate ligament reconstruction. A prospective randomized study. Am J Sports Med 1995;23:401-6 [see comment].

[11] Toutoungi DE, Lu TW, Leardini A, Catani F, O'Connor JJ. Cruciate ligament forces in the human knee during rehabilitation exercises. Clin Biomech 2000;15:176-87.

[12] Lu TW, O'Connor JJ, Taylor SJ, Walker PS. Validation of a lower limb model with in vivo femoral forces telemetered from two subjects. J Biomech 1998;31:63-9.

[13] Fleming BC, Beynnon BD, Renstrom PA, Peura GD, Nichols CE, Johnson RJ. The strain behavior of the anterior cruciate ligament during bicycling. An in vivo study. Am J Sports Med 1998;26:109-18.

[14] Komi PV. Relevance of in vivo force measurements to human biomechanics. J Biomech 1990;23(Suppl. 1):23-34.

[15] An KN, Berglund L, Cooney WP, Chao EY, Kovacevic N. Direct in vivo tendon force measurement system. J Biomech 1990;23:1269-71.

[16] Wilson DR, Feikes JD, Zavatsky AB, O'Connor JJ. The components of passive knee movement are coupled to flexion angle. J Biomech 2000;33:465-73.

[17] Torzilli PA, Deng X, Warren RF. The effect of joint-compressive load and quadriceps muscle force on knee motion in the intact and anterior cruciate ligament-sectioned knee. Am J Sports Med 1994;22:105-12.
[18] Shoemaker SC, Adams D, Daniel DM, Woo SL. Quadriceps/anterior cruciate graft interaction. An in vitro study of joint kinematics and anterior cruciate ligament graft tension. Clin Orthop 1993:37990.

[19] More RC, Karras BT, Neiman R, Fritschy D, Woo SL, Daniel DM. Hamstrings - an anterior cruciate ligament protagonist. An in vitro study. Am J Sports Med 1993;21:231-7.

[20] Bergmann G, Graichen F, Rohlmann A. Hip joint loading during walking and running, measured in two patients. J Biomech 1993;26:969-90.

[21] Davy DT, Kotzar GM, Brown RH, Heiple KG, Goldberg VM, Heiple $\mathrm{Jr}$ KG, et al. Telemetric force measurements across the hip after total arthroplasty. J Bone Joint Surg Am 1988;70:45-50.

[22] English TA, Kilvington M. In vivo records of hip loads using a femoral implant with telemetric output (a preliminary report). J Biomed Eng 1979;1:111-5.

[23] Rydell NW. Forces acting on the femoral head-prosthesis. A study on strain gauge supplied prostheses in living persons. Acta Orthop Scand 1966;37(Suppl. 88):1-132.

[24] Taylor ME, Tanner KE, Freeman MER, Yettram AL. Stress and strain distribution within the intact femur: compression or bending? Med Eng Phys 1996;18:122-31.

[25] Banks SA, Hodge WA. Accurate measurement of three-dimensional knee replacement kinematics using single-plane fluoroscopy. IEEE Trans Biomed Eng 1996;43:638-49.

[26] Mahfouz MR, Hoff WA, Komistek RD, Dennis DA. A robust method for registration of three-dimensional knee implant models to two-dimensional fluoroscopy images. IEEE Trans Med Imaging 2003;22:1561-74

[27] Komistek RD, Dennis DA, Mahfouz M. In vivo fluoroscopic analysis of the normal human knee. Clin Orthop 2003;410:69-81.

[28] Dennis DA, Mahfouz MR, Komistek RD, Hoff WA. In vivo determination of normal and anterior cruciate ligament-deficient knee kinematics. J Biomech 2005;38:241-53.

[29] Tsai T-Y, Lu T-W, Kuo M-Y, Hsu H-C, Kuo C-C. A voxel-based 2D/3-D registration method for measuring natural knee kinematics with single-plane fluoroscopy. IEEE Trans Med Imaging; submitted for publication.

[30] Zannoni C, Zannoni C, Viceconti M, Pierotti L, Cappello AACA. Evaluation of $\mathrm{CT}$ accuracy in orthopaedic implants geometry reconstruction. In: Proceedings of the Engineering in Medicine and Biology Society, 1997 Proceedings of the 19th Annual International Conference of the IEEE. 1997.

[31] Baltzopoulos V. A video fluoroscopy method for optical distortion correction and measurement of knee-joint kinematics. Clin Biomech 1995; 10:85-92.

[32] Weese J, Penney GP, Desmedt P, Buzug TM, Hill DL, Hawkes DJ, et al. Voxel-based 2-D/3-D registration of fluoroscopy images and CT scans for image-guided surgery. IEEE Trans Inf Technol Biomed 1997;1:284-93.

[33] Penney GP, Weese J, Little JA, Desmedt P, Hill DL, Hawkes DJ, et al. A comparison of similarity measures for use in 2-D-3-D medical image registration. IEEE Trans Med Imaging 1998;17:586-95.

[34] Li G, DeFrate LE, Park SE, Gill TJ, Rubash HE. In vivo articular cartilage contact kinematics of the knee: an investigation using dualorthogonal fluoroscopy and magnetic resonance image-based computer models. Am J Sports Med 2005;33:102-7.

[35] Li G, Moses JM, Papannagari R, Pathare NP, DeFrate LE, Gill TJ. Anterior cruciate ligament deficiency alters the in vivo motion of the tibiofemoral cartilage contact points in both the anteroposterior and mediolateral directions. J Bone Joint Surg Am 2006;88:1826-34.

[36] O'Connor J, Shercliff T, FitzPatrick D, Bradley J, Daniel D, Biden E, et al. Geometry of the knee. In: Daniel D, Akeson WH, O'Connor JJ, editors. Knee ligaments: structure, function, injury, and repair. Raven Press; 1990. p. 163-200.

[37] Lu T-W, Lin H-C, Hsu H-C. Influence of functional bracing on the kinetics of anterior cruciate ligament-injured knees during level walking. Clin Biomech 2006;21:517-24. 
[38] Markolf KL, Mensch JS, Amstutz HC. Stiffness and laxity of the knee-the contributions of the supporting structures. A quantitative in vitro study. J Bone Joint Surg Am 1976;58:583-94.

[39] Trent PS, Walker PS, Wolf B. Ligament length patterns, strength, and rotational axes of the knee joint. Clin Orthop 1976;117:26370.
[40] Lu TW, O'Connor JJ. Lines of action and moment arms of the major force-bearing structures crossing the human knee joint: comparison between theory and experiment. J Anat 1996;189:575-85.

[41] Chan SC, Seedhom BB. The effect of the geometry of the tibia on prediction of the cruciate ligament forces: a theoretical analysis. Proc Inst Mech Eng [H] 1995;209:17-30. 